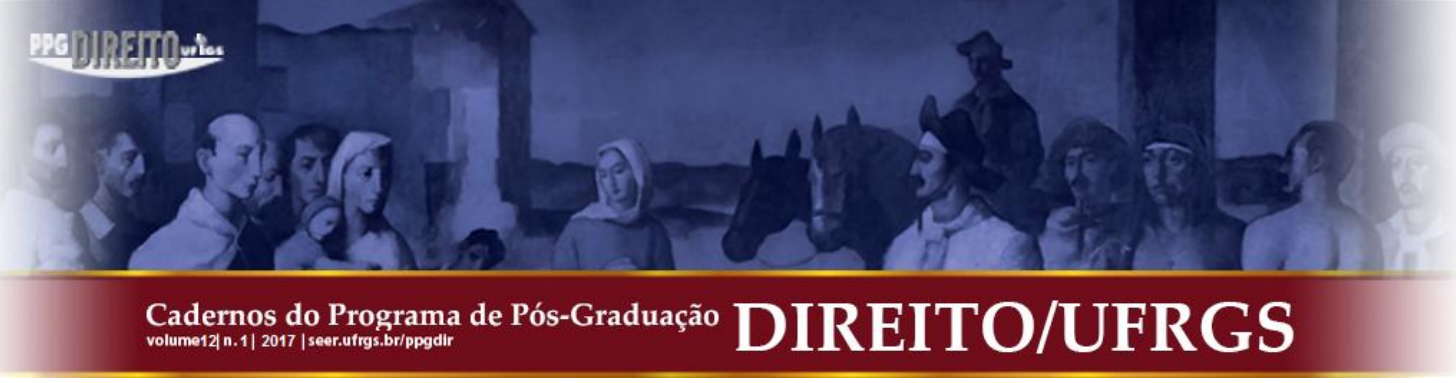

\title{
A ANÁLISE RETÓRICA NA TEORIA DO DIREITO
}

\author{
THE RHETORICAL ANALYSIS IN LEGAL THEORY
}

Pedro Parini*

\begin{abstract}
RESUMO: Este artigo tem por objetivo discutir as possibilidades de se empregar o esquema da retórica analítica ao estudo teórico do direito em seus diferentes níveis de discursividade e reflexividade. A abordagem retórico-analítica pressupõe três diferentes níveis de retoricidade da linguagem: o material, o prático e o analítico. Procuro estruturar a própria ideia de direito a partir deste ponto de vista retórico afim de esboçar uma teoria retórica do direito. Desse modo seria possível estabelecer três níveis para a retórica do direito: o nível mais básico da retórica material do próprio vocabulário empregado na confecção de textos normativos; o nível intermediário da retórica da dogmática jurídica; e, por fim, o nível mais elevado, do ponto de vista reflexivo da argumentação, da retórica analítica da teoria e da filosofia do direito. Se essa hipótese se confirma, será possível afirmar que o direito é um fenômeno essencialmente retórico, isto é, argumentativo e dependente dos discursos jurídicos em seus três diferentes níveis de retoricidade.
\end{abstract}

PALAVRAS-CHAVE: Retórica Analítica. Retórica Judicial. Teoria do Direito.

SUMÁRIO: Introdução. 1 Os Três Planos da Retórica do Direito. 2 Os Pilares Teóricos para a Construção da Análise Retórica do Direito. 3 Desdobramentos da Análise Retórica do Direito e da Dogmática Jurídica. 3.1 O Esquema da Retórica Analítica Aplicado ao Direito. 3.2 A Análise Fronética do Direito. 3.3 A Análise Holotática ou Holística do Direito. 3.4 A Análise Semiótica do Direito. Conclusão. Referências.

\section{INTRODUÇÃO}

O intuito deste estudo é promover o exame crítico, o desdobramento e a divulgação da retórica analítica proposta por Ottmar Ballweg, um dos poucos continuadores da tradição tópico-retórica iniciada por Theodor Viehweg na Escola de Mainz na Alemanha, além de propor o esquema da retórica analítica como método de investigação para a teoria do direito.

A tese de Ballweg a respeito da tripartição da retórica em três níveis distintos é tomada como pressuposto de desenvolvimento de uma retórica analítica, isto é, de um esquema interpretativo da própria retórica em sua imanência linguística e em suas estratégias de persuasão. Tradicionalmente, o que se entende por retórica é apenas o conjunto de técnicas voltadas à confecção de discursos persuasivos. Para esta visão do senso comum, a retórica não

\footnotetext{
* Pós-Doutor pela Università di Bologna. Doutor e Mestre pela Universidade Federal de Pernambuco (UFPE). Professor Adjunto do Departamento de Teoria Geral do Direito e Direito Privado da Universidade Federal de Pernambuco (UFPE). Coordenador do grupo de pesquisa "Retórica, Hermenêutica e Direito".
} 


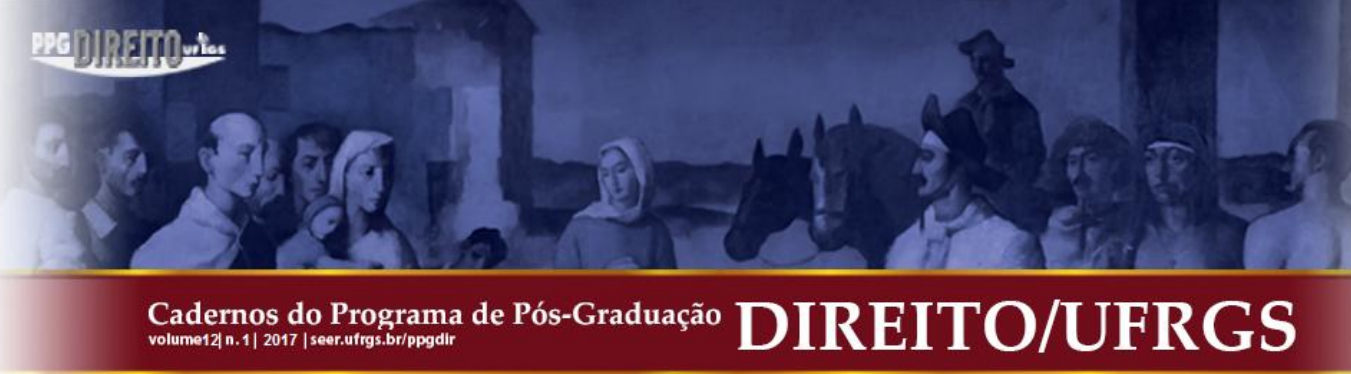

passa do nível de um mero conjunto de regras técnicas voltadas estrategicamente aos efeitos da persuasão, e nunca a um nível científico - ou analítico - de observação ou teorização sobre a função social das técnicas de persuasão, as características dos discursos persuasivos e a própria ideia de persuasão. Sem falar no caráter antropológico da retórica.

A metodologia da retórica analítica, empregada aqui como recurso para a análise de fenômenos jurídicos, assume esse papel científico, crítico e reflexivamente distanciado das necessidades práticas de persuasão da dogmática jurídica. Nada obstante, a retórica analítica, pelo fato de ser auto-reflexiva, seria capaz de ser compreendida como uma forma de teoria, mais abstrata e teórica em seus propósitos, mas ainda assim retórica. Isto é, a retórica analítica, apesar de sua atitude teorética e descritivista se reconhece como produto de discursos, argumentos, relatos e narrativas que visam a transmitir o conhecimento e levar à ação por meio do convencimento e da persuasão. A diferença entre a retórica analítica da teoria do direito e a retórica prática da dogmática está no fato de que na retórica analítica a persuasão assume um caráter científico demonstrativo que não pode estar presente na atividade dogmática em razão das necessidades concretas de decisão e fundamentação jurídicas.

\section{OS TRÊS PLANOS DA RETÓRICA DO DIREITO}

O direito pode ser visto como um caso especial não só de arte ou técnica retórica, mas como sendo imanentemente retórico no que se refere a seu vocabulário próprio, seus discursos e também no que diz respeito a sua produção de conhecimento. Falamos em três dimensões da retórica jurídica, porque a própria retórica pode ser compreendida de três diferentes modos

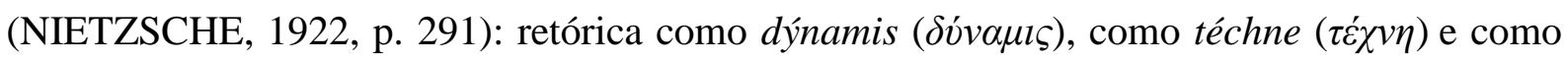

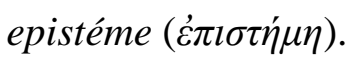

ARISTÓTELES (1996, p. 10 [I, 1355b]), explicitamente ambíguo - o que torna o trabalho moderno de tradução difícil e consequentemente variado - entende-a tanto como téchne quanto como dýnamis. Quando afirma que "ésto dè he rhetorikè dýnamis perì hékaston

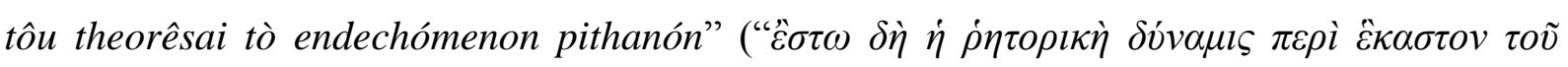

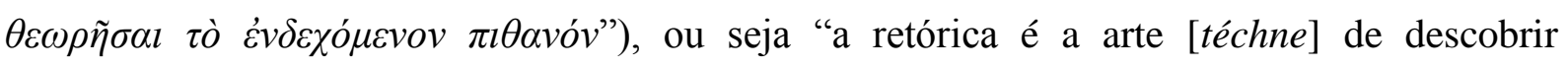


especulativamente o que em cada caso é próprio para persuadir"1, ou "a retórica pode ser definida como faculdade [dýnamis]de descobrir o possível meio de persuasão em relação a qualquer objeto", ou ainda "entendamos por retórica a capacidade [dýnamis] de descobrir o que é adequado a cada caso com o fim de persuadir"3, define-a como dýnamis, mas ao mesmo tempo leva os tradutores modernos a empregarem indistintamente as expressões "arte", "faculdade" ou "capacidade". Talvez isso se deva ao fato de que, logo em seguida, já nas linhas subsequentes de seu texto, o próprio Aristóteles usa reiteradas vezes a expressão téchne para se referir à retórica ou simplesmente mencioná-la, conectando-a também à noção de theoría $(\theta \varepsilon \omega \rho i ́ \alpha)$ e à ação de theoréo $(\theta \varepsilon \omega \rho \varepsilon ́ \omega)$.

Possivelmente foi em consideração a essa tripartição suscitada por Nietzsche nos seus estudos de retórica que Ottmar Ballweg tomou como pressuposto para sua teoria os três diferentes níveis de retórica: "material” como sendo, num primeiro nível, uma espécie de dýnamis típica e intrinsecamente humana; "prática" entendida como téchne e, no nível mais abstrato, a "analítica", como epistéme.

Neste sentido oferecido por Ottmar BALLWEG (1989, p. 230), ao modo de Nietzsche, portanto, é possível empregar a palavra retórica de três diferentes formas, ou seja, material, prática e analítica.

Procuro aplicar como modelo metodológico essa tripartição analítica da retórica para compreender o próprio direito em três diferentes níveis: o da retórica material de seus conceitos e metáforas, o da retórica prática dos modelos da dogmática jurídica e o da sua própria retórica analítica em forma de narrativas da teoria e filosofia jurídicas. Isso significa dizer que o direito também tem, do ponto de vista retórico-analítico, três níveis distintos: em primeiro lugar, o nível mais basal de sua retórica material, que também pode ser chamada de “existencial” (ADEODATO, 2013, p. 12) que é o nível da linguagem objeto dos juristas empregada na redação de textos normativos que formam leis, códigos, decretos, resoluções, portarias, emendas à constituição, a própria constituição, decisões judiciais, súmulas dos tribunais, precedentes, acórdãos, contratos, petições, sentenças, despachos - em suma, qualquer documento jurídico dotado de autoridade. Em segundo lugar, pode-se falar de uma retórica prática da linguagem dogmática do direito como as estratégias de sistematização,

\footnotetext{
${ }^{1}$ Da tradução francesa de Médéric Dufour.

${ }^{2}$ Da tradução italiana de Marco Dorati.

${ }^{3}$ Da tradução portuguesa de Manuel Alexandre Júnior. 
interpretação e manipulação da linguagem material dos textos normativos. E em terceiro lugar, teríamos a retórica analítica da teoria e da filosofia do direito com sua linguagem reflexiva, crítica e questionadora em relação à natureza, às características e à pertinência de se empregar tal ou qual conceito e de manipulá-lo dogmaticamente de diferentes formas.

Dessa forma, assumindo a analogia dos três níveis da retórica com os três níveis retóricos da linguagem jurídica, tem-se, em primeiro lugar, no sentido material, a própria retórica como objeto da análise retórica. Nesse sentido a linguagem é retórica e o que se evidencia a partir dessa constatação é o caráter retórico de toda a linguagem humana. BALLWEG (1991b, p. 176) diz que "a linguagem mesma é retórica. Ela tem todos os meios retóricos a seu alcance, cada um com a função específica que lhe é atribuída nos sistemas linguísticos sociais".

De fato, as retóricas materiais preenchem as funções básicas da vida ordinária como, por exemplo, funções de orientação, ordenação, regularidade, vinculação duradoura, posicionamento, relacionamento. Existe um processo de condensação da retórica material que, partindo da linguagem comum, resulta nas linguagens especializadas, como as linguagens de controle do direito, do dinheiro, do poder, do amor, dos mitos, das religiões. Cada sistema linguístico que forma cada um desses âmbitos específicos constitui um vocabulário filtrado da linguagem comum, isto é, da retórica material da linguagem ordinária. Assim, no caso da retórica material do direito, palavras como, por exemplo, justiça, igualdade, liberdade, dignidade, pena, retribuição, Estado, democracia, autoridade, respeito, boa-fé etc. que formam um vocabulário essencial a essa retórica material do direito, exercem funções específicas que podem ser diferentes ou coincidentes - tanto no âmbito da linguagem comum quanto no âmbito das linguagens especializadas de controle, como é o caso da linguagem especializada do direito.

Essas funções, contudo, podem ser, segundo BALLWEG (1991b, p. 177), mais bem desempenhadas caso sejam mantidas latentes. Seria o caso das expressões por mim acima citadas e as que o próprio Ballweg oferece como exemplo. Ele afirma que quando se fala aparentemente em "verdade" está latente o sentido de "ordem"; ou quando uma teoria propõese a produzir "conhecimento", o sentido latente seria o de "orientação"; ou quando se fala em "racionalidade" tem-se na verdade "regularidade"; para o grandioso verbo "ser" a ideia subjacente seria a de uma simples "vinculação duradoura"; a latência também está presente quando se fala em "direitos", no lugar de "posicionamento", ou de "responsabilidade", no 
lugar de "relacionamento". Isso quer dizer que diversos vocábulos são explicitados com o objetivo de manter latentes significados diferentes que revelam sua verdadeira função de controle e predição. A retórica analítica seria em tese capaz de desentranhar esses significados da retórica material e essas funções latentes da retórica prática.

De acordo com Ballweg, portanto, o jurista quando recorre à palavra "verdade" quer significar outra coisa diferente da verdade que o próprio direito é incapaz de prover. A palavra "verdade" empregada pelo jurista quer dizer qualquer coisa, menos literalmente verdade. O mesmo acontece com "racionalidade". Ballweg pensa ser mais honesto aos juristas valer-se da expressão "regularidade" (Regelhaftigkeit) ao invés de racionalidade. "Regularidade", pois, seria mais justo ou oportuno, ou mesmo mais exato do que "racionalidade" quando empregada em discursos jurídicos de qualquer tipo. Em todo caso, de acordo com ele, falar em "regularidade" seria menos enganador ou desorientador (BALLWEG, 1989, p. 229).

Dessa forma, a esse artifício linguístico de usar uma palavra no lugar de outra - como, por exemplo, racionalidade no lugar de regularidade - que BALLWEG (1991b, p. 177) chama de "redenominação com significado existencial" eu chamo de ironia (existencial), por meio da qual, por exemplo, a vingança ao se tornar justiça, se legitima e garante assim sua credibilidade e sua confiança, sendo capaz de continuar a exercer suas funções, mesmo que de forma latente (PARINI, 2014). A vingança, apesar de repudiada em um contexto moderno, continua existindo, mesmo que não verbalizada ou explicitada, porque é redenominada como justiça. Enquanto vingança, num vocabulário originário da retórica material da linguagem comum, se torna historicamente ilegítima, irracional, desautorizada e pessoal, por meio de outra expressão, como justiça, ela se legitima, se racionaliza e é dotada da autoridade impessoal do direito e do Estado.

O segundo sentido para a palavra identifica a retórica como sendo uma doutrina orientada à efetividade ou à realização dos discursos persuasivos. Este é o sentido tradicional das retóricas práticas compromissadas com os objetivos de produção de efeitos retóricos de persuasão e submetidas aos constrangimentos dogmáticos da obrigatoriedade de fixar textos normativos, da obrigatoriedade de interpretar esses textos de acordo com certos cânones previamente estabelecidos, da obrigatoriedade de argumentar exclusivamente com base nesses textos interpretados, da obrigatoriedade de decidir e da obrigatoriedade de fundamentar (BALLWEG, 1991b, p. 179). 


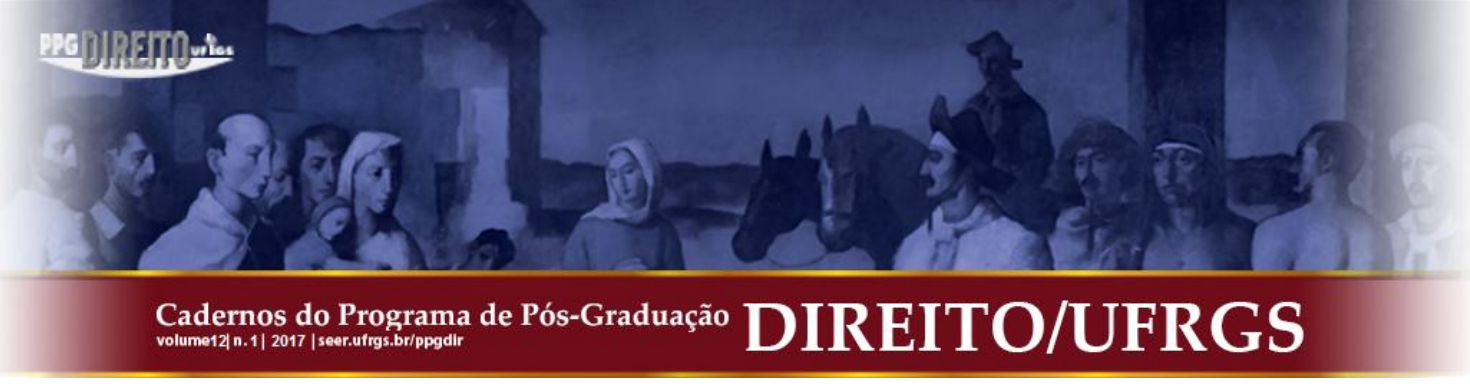

É nesse âmbito da retórica prática que se desenvolvem as técnicas para a manipulação efetiva da retórica material, incluindo o aprendizado que vem com a experiência, ou com a observação e as possíveis reflexões que têm a finalidade de fundamentar teoricamente a atividade prática organizando-a em um saber tecnológico. Nas palavras de BALLWEG (1991b, p. 178), "as retóricas práticas ensinam o emprego transcendente dos meios retóricos imanentes à linguagem, objetivando a transmissão das dóxai tal como estas são reunidas nas dogmáticas, na intenção de persuadir, convencer ou fazer crer”. Fazem parte da retórica prática disciplinas como a doutrina da tópica, o estudo da argumentação, as artes do estilo e das figuras de linguagem, assim como desenvolvimentos lógicos ligados ao entimema e ao paradigma (PARINI, 2015), além das técnicas de interpretação e da dogmática hermenêutica.

Assim, o jurista, perito em manipular a retórica material do direito, é capaz de jogar com palavras que, do ponto de vista semântico, tudo e nada significam. As técnicas de manipulação do vocabulário jurídico fazem parte das retóricas práticas da dogmática jurídica. De acordo com BALLWEG (1991b, p. 178), “essas retóricas práticas, formais, na medida em que procuram chamar atenção para a dependência da situação e para o auditório, deveriam, enquanto conhecem a ambigüidade da língua, garantir um trânsito efetivo e bem-sucedido no trato com as retóricas materiais". Perceba-se que manipulação, ironicamente, não tem qualquer conotação pejorativa, mas é uma condição ou garantia de credibilidade dos discursos dos dogmáticos. O fato de os juristas dogmáticos serem capazes de dominar e manipular a vagueza e a ambiguidade do vocabulário jurídico é fundamental para que se aceite como certo ou verdadeiro o que eles afirmam e impõem como certo ou verdadeiro.

Por fim, o terceiro sentido é o de retórica como metarretórica (BALLWEG, 1989, p. 232), ou seja, como uma retórica analítica. Em sua função analítica a retórica não está submetida aos mesmos constrangimentos das retóricas material e prática, mas a outros inteiramente diferentes como

a limitação a enunciados formais; a consideração permanente de que tais enunciados podem vir a se tornar empíricos; a necessidade de sua complementação através de outros princípios analíticos; a possibilidade de controle das proposições teóricas e sua compatibilidade com outras teorias analíticas; o caráter parcial das análises e de seus resultados, assim como a possibilidade de reprodução, acumulação e generalização dos mesmos (BALLWEG, 1991b, p. 179). 
A retórica analítica, pois, tem como objetivo investigar - de forma não dogmática - a estrutura e o modo de funcionamento dos outros dois âmbitos de aplicação retóricos sem que haja qualquer espécie de compromisso com as estratégias de persuasão da retórica prática. A análise retórica tem o papel apenas descritivo e não prescritivo - por essa razão, não dogmático - de averiguar tanto o conteúdo das retóricas materiais, como as regras formais das retóricas práticas, isto é, dos aspectos internos à própria práxis dogmática prescritiva (BALLWEG, 1989, p. 232). Assim, a retórica analítica se funda em um ponto de vista externo-analítico que é capaz de perceber as relações entre sujeitos, objetos e sinais desde diferentes perspectivas (fronética, holística e semiótica). Externamente a retórica analítica visualiza as construções dos sistemas linguísticos sociais levando em consideração o seu caráter autorreferente e autopoiético (BALLWEG, 1991b, p. 180). O desenvolvimento de uma retórica analítica tem como objetivo, portanto, a elaboração de um "retículo" analítico capaz de decifrar o caráter retórico de sistemas linguísticos complexos como os da linguagem do direito, da economia, da moral, da política, da história, da sociedade, da arte, da filosofia, da religião e, num sentido geral, de todas as humaniora e da linguagem cotidiana, no sentido de uma linguagem impositiva, normativa ou prescritiva (BALLWEG, 1989, p. 231).

Em primeiro lugar, no âmbito da fronética, a análise retórica parte da compreensão de uma relação de interação linguisticamente imanente entre sujeitos $(S \rightarrow S)$ a que Ballweg chama de agôntica, para depois passar à análise retórica da relação entre sujeito e objeto $(\mathrm{S} \rightarrow$ O), denominada ergôntica, até chegar à dimensão pitanêutica da relação persuasiva do sujeito em relação à manipulação do sinal $(\mathrm{S} \rightarrow \mathrm{Z}$ ). Em segundo lugar, no âmbito da holística (ou holotática como Ballweg a chamou inicialmente), a retórica analítica se subdivide em ontotática destinada à análise retórica das ontologias que se fundam na interação entre objetos $(\mathrm{O} \rightarrow \mathrm{O})$, em axiotática, com o estudo das relações determinantes entre objeto e sinal $(\mathrm{O} \rightarrow$ $Z)$ e em teleotática que estuda as relações finalísticas entre objeto e sujeito $(\mathrm{O} \rightarrow \mathrm{S})$. Por fim, a retórica analítica se completa com o já tradicional âmbito da semiótica composto de sintaxe $(Z \rightarrow Z)$, semântica $(Z \rightarrow O)$ e pragmática $(Z \rightarrow S)$.

A necessidade de estabelecer esses diferentes âmbitos ou dimensões da análise retórica não implica que o objeto da retórica seja repartido ou desmembrado em vários objetos diferentes. Pelo contrário, BALLWEG (1989, p. 232) afirma que a subdivisão da retórica tem apenas um escopo puramente analítico e que o objeto da análise, a saber, o os sistemas linguísticos - embora desmembrado em razão da analiticidade do próprio procedimento - 
deve ser compreendido como um "todo", isto é, como um todo situativo no interior de um sistema linguístico social que se constitui em uma unidade multidimensional.

\section{OS PILARES TEÓRICOS PARA A CONSTRUÇÃO DA ANÁLISE RETÓRICA DO DIREITO}

Voltando aos pressupostos que sustentam a tripartição da retórica, para a confecção do esboço de um uma retórica analítica, Ballweg parece se apoiar em dois grandes pilares da reflexão teorética: em primeiro lugar, o sistema filosófico de Aristóteles e, em segundo lugar, mas não de maneira menos importante, a retórica filosófica de Friedrich Nietzsche.

De acordo com a classificação do conhecimento fornecida por Aristóteles, que distingue pelo menos quatro formas do pensar humano: póiesis, phrónesis, epistéme e sophía, BALLWEG (1989, p. 229) procura estabelecer diferentes níveis também para o pensamento retórico. Esses três níveis vão desde uma perspectiva imanente da atividade irrefletida de uso da própria linguagem, passando pelo desenvolvimento tecnológico de estratégias de manipulação dessa linguagem, até o nível mais abstrato - e de certa forma transcendente - de análise e reflexão acerca dos outros dois níveis mais imanentes da retórica.

Ao mesmo tempo, contudo, em que recorre à diferenciação aristotélica, Ballweg não aponta exatamente a quais desses âmbitos correspondem os de sua tripartição da retórica. De qualquer modo, a retórica pode ser equiparada a todas essas formas de pensamento categorizadas na filosofia antiga, seja como póiesis, na produção efetiva de discursos persuasivos, ou como phrónesis, isto é, enquanto sabedoria prática ligada diretamente à experiência argumentativa a que nos submetemos cotidianamente, ou ainda como epistéme ou estudo analítico-científico do próprio caráter retórico de toda a linguagem. Como sophía, a retórica seria tomada num sentido filosófico, como a sabedoria capaz de determinar todo o pensar humano como o desenvolvimento comunicacional linguístico-dependente de toda formulação intelectual. Mas não podemos dizer que a este nível corresponde exatamente o que Ballweg denomina de retórica analítica. Especialmente diante de sua constante afirmação de que retórica não é filosofia (BALLWEG, 1982, p. 28) e tampouco deseja sê-lo (BALLWEG, 1989, 230), mesmo que a construção filosófica seja sempre acompanhada da desconstrução retórica (BALLWEG, 1989, 229). 
De qualquer forma, é provavelmente no sentido prático e no analítico que BALLWEG (1989, p. 229) afirma que "retórica é uma das mais antigas formas de esclarecimento". Apesar de não ser objetivo da retórica a defesa de qualquer tipo de ideologia iluminista do esclarecimento, o próprio esclarecimento não pode ser considerado um privilégio da filosofia (BALLWEG, 1989, p. 230). De fato, descobrir como dominar o discurso e os modos de persuasão (e, além disso, ser capaz de refletir sobre a que se deve a própria persuasão) é o ponto mais original de tomada de consciência sobre as formas de existência tipicamente humanas relacionadas à manipulação da linguagem, ou seja, da retórica material, dos conceitos e metáforas que formam o nosso mundo real, ou seja, é uma forma de esclarecimento.

Ballweg ainda se inspira em Nietzsche quando este afirma que "a própria linguagem é retórica, pois ela quer transmitir apenas uma dóxa e não uma epistéme" (NIETZSCHE, 1922, p. 298). Essa afirmação talvez seja justamente o pressuposto ou ponto de partida filosófico para o estabelecimento de uma teoria analítica da retórica. Segundo o próprio BALLWEG (1989, p. 230), é nessa afirmação que se encontram sinteticamente os três distintos sentidos ou modos de emprego da palavra retórica. "A própria linguagem é retórica" se refere à linguagem objeto da retórica material, isto é, da linguagem que empregamos em nossa comunicação. O sentido de retórica prática está no fato de que aprender e ensinar a usar essa retórica material de maneira efetiva e eficiente dependem do estabelecimento de doutrinas retóricas orientadas para a prática. E o sentido de retórica analítica está pressuposto na própria afirmação, no sentido de que é possível assumir, como fez Nietzsche, um ponto de vista externo metalinguístico e analítico a respeito da própria retórica, tanto no nível material da própria linguagem humana, quanto no prático das doutrinas retóricas (BALLWEG, 1989, p. 231).

BALLWEG (1989, p. 232) estabelece que o objetivo da retórica analítica não é o de prescrever como a retórica deve funcionar, seja nos níveis material ou prático, mas de descrever, a partir de uma intentio zetetica, o seu modo próprio de operar. Ou seja, a retórica analítica não dita regras para a manipulação retórica da linguagem, mas ao contrário, procura descrever o que são essas regras e quais os seus fundamentos. A própria intentio dogmatica de estabelecer regras técnicas que devem ser observadas na construção discursiva é também um

\footnotetext{
${ }^{4}$ „Rhetorik ist eine der ältesten Formen der Aufklärung”.

5 „Die Sprache selbst ist Rhetorik, denn sie will nur eine dóxa, keine epistéme übertragen”. 


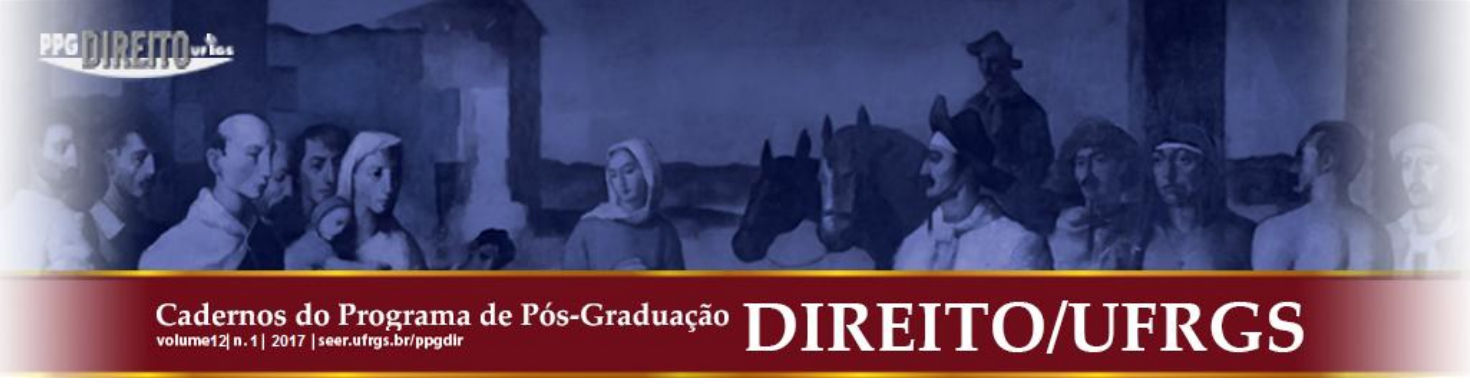

objeto da análise retórica. Mas, da mesma forma, a retórica analítica não prescreve como deve ser essa dogmática ou esse conjunto de regras técnicas.

Assim, pois, a retórica analítica tem como objeto de investigação tudo o que faz parte do sistema linguístico, ou seja, os seus símbolos e as suas respectivas relações. Nesse aspecto a retórica analítica se aproxima da semiótica e com ela divide as mesmas dificuldades (LAUNHARDT, 2005, p. 154). Assim a retórica, da mesma forma que a semiótica, reconhece sua imanência sistêmica em relação à própria linguagem, dado que também se define simbolicamente, assim como os utentes de uma língua, em um mesmo plano (BALLWEG, 1989, p. 233). Isso quer dizer que um ponto de vista realmente externo, isto é, situado fora dos sistemas linguísticos e simbólicos é apenas uma forma retórica de lidar com o problema. Não há como deixar de fazer retórica mesmo que seja para analisar a retórica. Nada mais irônico para a retórica analítica do que a frase "isso não passa de retórica”, como se a afirmação, ela própria, não constituísse uma retórica e também fosse constituída por uma retórica.

\section{DESDOBRAMENTOS DA ANÁLISE RETÓRICA DO DIREITO E DA DOGMÁTICA JURÍDICA}

\subsection{O Esquema da Retórica Analítica Aplicado ao Direito}

Pretendo relacionar a tripartição da retórica a uma possível tripartição tópica do direito, isto é, uma tripartição que leva em consideração os diferentes "lugares" ou níveis de reflexividade discursiva do direito. A noção de direito é provavelmente tão vaga e ambígua quanto a noção de retórica. Como visto, da mesma forma que retórica pode significar ao menos três coisas distintas (retórica material, prática e analítica), direito pode ser entendido de três diferentes maneiras: direito como técnica, direito como tecnologia e direito como teoria.

O ponto de partida ou de inspiração para essa tripartição do direito em diferentes níveis é a definição de dogmática jurídica proposta por Tercio FERRAZ JR. (1980). Além disso, a proposta de tripartição da retórica como método, metodologia e metódica (ADEODATO, 2013) pode ser considerada uma analogia semelhante a que apresento. Os desdobramentos, contudo, dessa visão são de minha responsabilidade. 


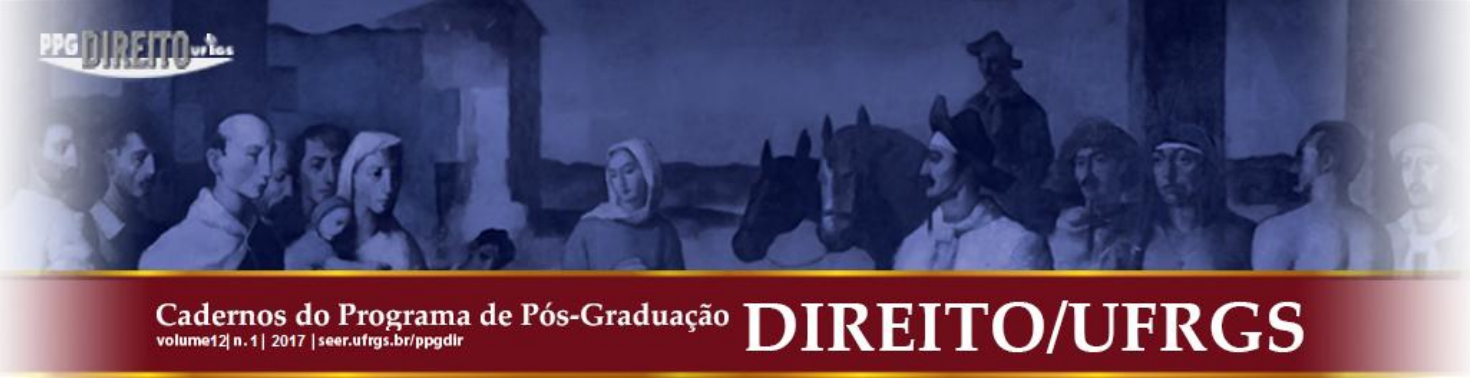

O direito como técnica seria o próprio direito positivo. No caso da modernidade, o direito dogmático positivo vigente em uma determinada sociedade situada no tempo e no espaço. O conjunto de normas de um espaço territorial geopoliticamente determinado representado pelo modelo do ordenamento jurídico hierarquicamente estruturado é o que se pode chamar de direito como técnica de solução de determinados tipos de conflitos e de neutralização de formas específicas de dissenso.

O direito como tecnologia se refere à dogmática jurídica. As técnicas de produção de normas e decisões, de inferências e interpretações do direito já possuem um grau de reflexividade que não se vislumbra no plano do direito como técnica, isto é, como sistema de normas positivadas. Assim, há uma "transformação do raciocínio dogmático em teoria dogmática” (FERRAZ Jr., 1980, p. 62). Isso significa dizer que a tecnologia enquanto estudo da técnica assume um relativo senso crítico-reflexivo em seus discursos.

Assim, o pensamento tecnológico não chega a ser um sistema normativo, embora esconda alguma coisa de prescritivo. Ele não se opõe à ciência, mas a prolonga, realizando operações transformadoras consistentes na relevância atribuída a certas conclusões das teorias científicas para a solução de problemas práticos (FERRAZ Jr., 1980, p. 90).

O direito como teoria assumiria um grau ainda maior de reflexividade em relação à dogmática enquanto tecnologia em virtude de seu necessário distanciamento crítico em relação ao direito positivo e, em certa medida, também à dogmática. A teoria do direito poderia ser entendida, pois, como "teoria da teoria", ou "observação da observação", ou ainda "reflexividade discursiva do reflexo discursivo dogmático do próprio ordenamento jurídico". Levando em consideração a tripartição proposta por ADEODATO (2013), pode-se dizer que a teoria do direito ou a ciência do direito não dogmática está no nível de uma metódica.

A atitude metódica é analítica, que não é mais dogmática. A retórica tem três níveis, mas a dogmática só tem dois porque, no terceiro nível, ela já se transforma em algo mais próximo do que se pode denominar uma ciência sobre o direito. Isso porque é descritiva e assume uma pretensão de neutralidade, exatamente por não ser normativa. Seu objeto material são os outros dois níveis retóricos, o material e o estratégico, assim como, sobretudo, as relações entre eles (ADEODATO, 2013, p. 17).

Assim, neste último plano analítico, podemos subdividir a teoria do direito de acordo com o esquema de análise retórica proposto por Ballweg. Dessa forma, teríamos uma teoria retórico-analítica do próprio direito. Isto é, a própria reflexão teórica do direito seria retórica em sua forma de operar enquanto análise de técnicas e tecnologias de persuasão e 


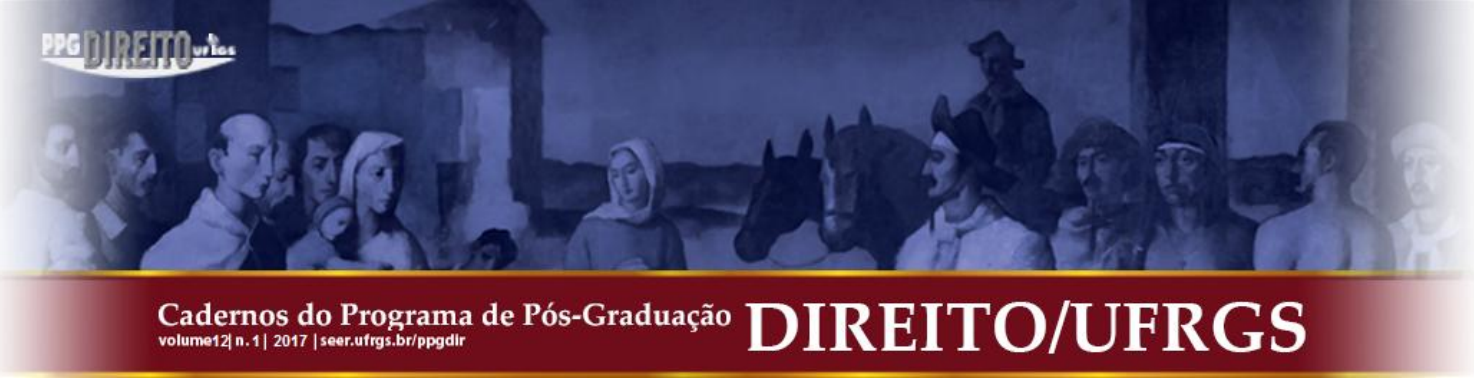

neutralização do dissenso. A teoria retórica do direito seria, assim, formada por análises discursivas da retórica material e da retórica prática do direito.

Esquema da retórica analítica

\begin{tabular}{|l|}
\hline Fronética: \\
Agôntica $(\mathrm{S} \rightarrow \mathrm{S})$ \\
Ergôntica $(\mathrm{S} \rightarrow \mathrm{O})$ \\
Pitanêutica $(\mathrm{S} \rightarrow \mathrm{Z})$ \\
\end{tabular}

Holística:
Ontotática $(\mathrm{O} \rightarrow \mathrm{O})$
Axiotática $(\mathrm{O} \rightarrow \mathrm{Z})$
Teleotática $(\mathrm{O} \rightarrow \mathrm{S})$

\begin{tabular}{|l|}
\hline Semiótica: \\
Sintaxe $(Z \rightarrow Z)$ \\
Semântica $(Z \rightarrow O)$ \\
Pragmática $(Z \rightarrow S)$ \\
\end{tabular}

\subsection{A Análise Fronética do Direito}

Na primeira parte da fronética, a agôntica, estudam-se as relações entre os sujeitos ( $\mathrm{S}$ $\rightarrow \mathrm{S})$ que são responsáveis pela construção linguística do mundo que é reconhecido como sendo o mundo (real, imaginário, ideal, irreal, simbólico, empírico, cultural etc.). Nesta dimensão da fronética, observa-se a maneira de agir e os padrões pelos quais os sujeitos se inter-relacionam (ADEODATO, 2009, p. 42).

No âmbito da teoria geral do direito e da filosofia do direito, a análise agôntica da fronética corresponde às teses sobre status jurídico e papel social, sobre reconhecimento, integração, coordenação e subordinação, cooperação e conflito, isto é, sobre as posições que ocupam os sujeitos dentro desses vários mundos a que chamamos real, ideal, imaginário etc. que são formados pelas inúmeras retóricas materiais de diferentes âmbitos (do direito, da religião, da economia, da ciência, da política, da história etc.). Assim, determina-se de antemão nas teorias jurídicas quem pode e quem não pode figurar como sujeito de direitos e de deveres, quem deve ou não deve ter considerada a sua personalidade jurídica, as relações de igualdade e desigualdade, de coordenação e subordinação, de autoridade, de competência, de responsabilidade, de bilateralidade atributiva, de entrelaçamento, dentre várias outras referentes à luta pelo reconhecimento de cada um no interior de uma comunidade. Esse embate entre diferentes sujeitos na conformação do que concebemos como mundo é aludido na própria expressão agón ( $\dot{\alpha} \gamma \omega \dot{v}$ ), de onde vem o termo Agontik escolhido por BALLWEG (1989, p. 245; 1991a, p. 48; 1991b, p. 180), que representa uma assembleia, uma arena, um lugar de encontro, de combate ou o próprio combate, concurso ou disputa, trabalho, esforço e 


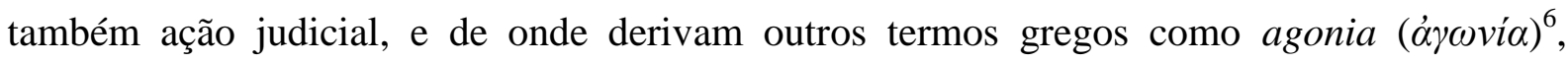

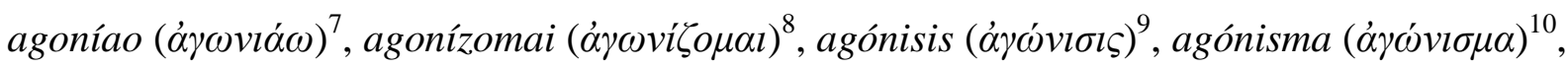

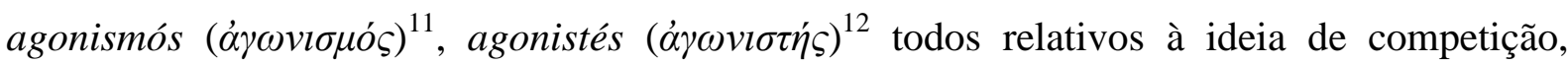
combate, disputa e contenda, inclusive no sentido especificamente jurídico. A escolha da expressão Agontik e não Agonistik, isto é, agôntica ao invés de agonística que vem de agonistés, pode revelar um caráter mais amplo do que a simples noção de rival, de mero combatente, ou mesmo de advogado, e se referir também a situações públicas de cooperação, de coordenação. Se na agonística está escancarada a noção de combate, de vitória e de vencedor, na agôntica pode-se incluir também a discussão comum num ambiente em que os debatedores cooperam para um mesmo fim e em que a disputa não tem necessariamente um vencedor e um perdedor. De qualquer forma, ambos os termos estão ligados à noção de luta ou disputa que parece ser essencial à própria ideia de direito, ou seja, de conflito de interesses, de violência e de coercitividade.

Em um segundo âmbito da fronética, a ergôntica, examinam-se as relações entre sujeito e objeto $(\mathrm{S} \rightarrow \mathrm{O})$. As teorias jurídicas que pertencem a esse âmbito estudam as relações jurídicas, os contratos, as obrigações e as próprias noções de direito e de dever que se relacionam com os sujeitos, ou seja, tudo aquilo que é considerado objeto em relação a um sujeito. Nesse âmbito é que surgem, por exemplo, as diferentes teses sobre se a relação jurídica que envolve direitos reais se dá entre dois sujeitos, sendo um deles o sujeito passivo universal, ou se a relação é entre o sujeito e a coisa. Mais abstratamente ainda discute-se o que pode vir a ser objeto de um direito, isto é, o que pode ser objeto em relação a determinado sujeito e o que é o objeto do próprio direito compreendido objetivamente como norma ou ordenamento. Ergontik (BALLWEG, 1989, p. 186; 1991a, p. 48; 1991b, p. 180), provavelmente vem de érgon (Ë $\rho \gamma o v$ ) que significa fato, realidade, trabalho, o próprio produto do trabalho, mas também coisa, matéria, pedaço, circunstância. Adeodato estende o significado até a noção de "efetividade", ou "realidade", ou ainda "realidade efetivada", em alemão Wirklichkeit. É justamente nesse âmbito que os sujeitos determinam o que é o "mundo

\footnotetext{
${ }^{6}$ Luta, esforço, argumentação, discussão; medo, agonia.

${ }^{7}$ Rivalizar, competir, irritar-se, ser assediado.

${ }_{9}^{8}$ Lutar, contender, seguir com uma ação judicial, falar publicamente, esforçar-se para fazer algo.

${ }^{9}$ Combate.

${ }^{10}$ Torneio; ação judicial; prêmio; coisa esplendorosa; bravura.

${ }^{11}$ Discussão, competição.

${ }^{12}$ Competidor, rival, campeão; advogado, defensor.
} 
real" do direito, quais são as "coisas" do direito, aquilo que pode ser reificado pelo direito como algo material ou substancialmente válido. É assim que se passa de estratos mais concretos como, por exemplo, a posse efetiva e direta de uma coisa móvel a estratos mais abstratos como o direito de propriedade intelectual sobre uma ideia, um som, um desenho, um texto, ou mesmo a noção dogmática de direito subjetivo.

No que se refere à relação ergôntica na teoria do direito deve-se considerar que não se pode separar o autor de sua obra: "o que um homem é se estende a suas obras" (JHERING, 1974, p. 133). Há uma profunda ironia em tentar separar as duas coisas quando se trata de "ciência jurídica". A pessoa do cientista, do ponto de vista epistemológico, em tese, não teria importância, pois o que é relevante são suas hipóteses, provas e conclusões. Da mesma forma acontece com a própria dogmática jurídica que despersonifica (despessoaliza, des-subjetiviza) o intimamente pessoal e subjetivo que existe em uma decisão judicial, em um ato administrativo, ou na criação de uma lei. O que importa para a dogmática em sua mímica epistemológica não é a pessoa física do juiz, ou do legislador, ou do agente da administração pública. É como se toda criação e aplicação do direito fossem independentes de um sujeito e de todas as circunstâncias que envolvem e determinam sua existência. Melhor seria não levar em consideração o sujeito, o indivíduo, ou o conjunto de indivíduos que têm interesses concretos, cujas escolhas são determinadas em razão de sua ideologia e visão de mundo, e ficar com o dado objetivo: a norma, a lei, o ordenamento jurídico. No lugar do juiz (indivíduo), tem-se o juiz (órgão do judiciário). Essa forma objetivadora do pensamento jurídico é altamente sofisticada e depende também, claramente, de uma retórica da objetivação.

Muito dificilmente as supostas análises objetivas da filosofia e da teoria do direito estão desvinculadas de uma ideologia particular ou de uma visão de mundo própria do jurista filósofo ou teórico. É o que se vê, por exemplo, no caso em que juízes, mesmo quando não estejam desempenhando a sua função institucional, mas estejam atuando exclusivamente naquele momento como pesquisadores ou cientistas do direito, não conseguem se despir completamente do seu papel, ou fazer uma análise neutra, imparcial ou objetiva da "realidade" do direito.

Por último, ainda na fronética, a pitanêutica estuda as relações entre sujeito e sinal ( $\mathrm{S}$ $\rightarrow$ Z) referente às prescrições dos sinais que se deve utilizar nos vários domínios específicos de um sistema linguístico. Assim, no direito, em cada âmbito da dogmática jurídica há uma 
integra. Esse processo de ontologização dos significados em um ser determina a relação entre objetos $(\mathrm{O} \rightarrow \mathrm{O})$. Agora não se está mais no âmbito de domínio dos sujeitos sobre os objetos, mas dos próprios objetos em relação a outros objetos em uma realidade aparentemente independente de qualquer sujeito e objetiva em si mesma. É o que $\operatorname{ADEODATO~(2009,~p.~41)~}$ chama de "ontologismo" ou "objetivação retórica totalizadora dirigida ao próprio objeto". É assim que se permite à teoria e à filosofia do direito falar de um direito sem autoria, como um direito natural racional, ou de regras em si mesmas racionais, por exemplo, ou ainda de uma norma fundamental que não é posta por ato de vontade algum e fundamenta todo o ordenamento jurídico, ou de uma vontade despsicologizada da própria norma jurídica, ou de alguma ideia jurídica que existe em si mesma e vale de per si etc. A expressão Ontotatik de BALLWEG (1989, p. 244; 1991a, p. 48; 1991b, p. 181) está relacionada à ideia filosófica da

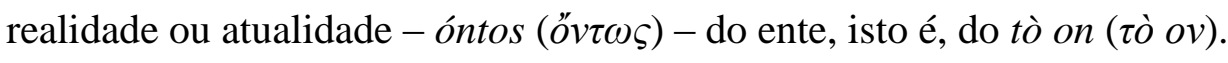

Essa relação objetual se reforça na relação axiotática, isto é, a relação de um objeto com um sinal $(\mathrm{O} \rightarrow \mathrm{Z})$ que determina o valor do próprio sinal. $\mathrm{O}$ que significa dizer que, nesse âmbito, o objeto exerce uma relação de domínio sobre o sinal. Na axiotática, portanto, o sinal assume uma função secundária em relação ao objeto, como se houvesse uma dependência do nome em relação ao ser da coisa. É o que se pode denominar "objetivismo linguístico" (ADEODATO, 2009, p. 41). É nesse âmbito que as teorias se perdem em suas classificações, categorizações e taxonomias. Axiotatik, como escolhido por BALLWEG (1989, p. 244; 1991a, p. 48; 1991b, p. 181), se refere a áxios (ä̋̆loৎ) que quer dizer valioso, equivalente, precioso, conveniente, meritório, certo ou próprio. Daí o nome certo, o conceito justo, representarem algo tão valioso para algumas formas de pensar o direito que acreditam ser a compreensão do jurídico apenas uma consequência de sua definição. No fundo, a retórica analítica, justamente por ser analítica, compartilha de algum modo essa forma de pensamento.

Por fim, ainda faz parte da holotática, a teleotática que analisa as relações entre objeto e sujeito $(\mathrm{O} \rightarrow \mathrm{S})$. Na teleotática essas relações são, assim como na axiotática, também valorativamente determinantes ou normativas, nas quais há agora um domínio dos objetos não mais sobre os sinais, mas sobre os sujeitos. Aqui o ser objetual das coisas determina a posição dos sujeitos. Há, na teleotática, portanto, também uma "objetivação retórica totalizadora dirigida ao sujeito" a que se pode chamar de "subjetivismo" (ADEODATO, 2009, p. 41). O indivíduo deixa de ser único em sua individualidade subjetiva para assumir posições 


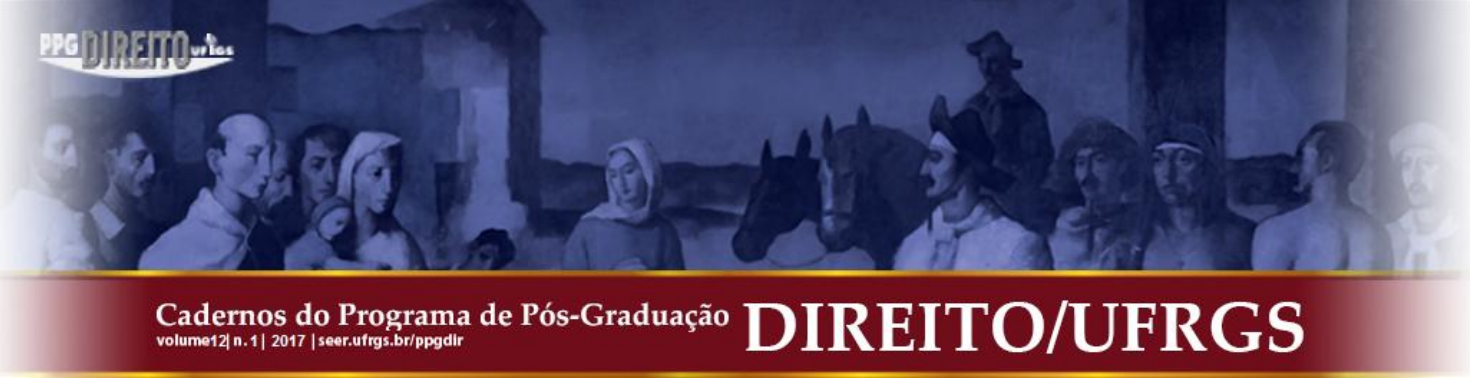

sujeito termina ficando em segundo plano em relação ao sinal, o que não acontece no âmbito especialmente retórico da fronética, no qual o próprio sinal pode ser suprimido, mesmo que apenas momentaneamente, na análise das relações entre sujeitos da agôntica $(S \rightarrow S)$. Como afirma João Maurício ADEODATO (2009, p. 41):

\begin{abstract}
A análise retórica fronética ou prudencial tenta ir adiante, na medida em que não mais enfatiza o signo, como a semiótica, mas sim os próprios participantes que se utilizam da comunicação, os utentes. Ela constitui a atitude retórica propriamente dita, é a atitude tomada pelo retórico analítico, pois lhe dá uma perspectiva além da material, na qual todos estão imersos, e da prática, que é dominada pelo técnico, pelo especialista.
\end{abstract}

Adeodato prefere a expressão "utente" ao invés de "sujeito", provavelmente assumindo uma perspectiva precipuamente pragmática em que o "uso" se destaca dentre outras funções da língua. Prefiro manter a terminologia adotada originalmente por Ballweg que, apesar de mais tradicional, saturada, hipertrofiada e impregnada de preconceitos de diferentes sistemas filosóficos, ainda é mais abrangente e supera a própria ideia de pragmática ou do uso da linguagem. Se falo em "utente", destaco o caráter pragmático do sujeito, ou faço da retórica um ramo da semiótica, isto é, da pragmática. Já se falo em sujeito, de forma mais abrangente, faço da pragmática uma espécie subordinada do gênero retórica e não mais exclusivo da semiótica.

A transposição do esquema da retórica analítica para a teoria do direito não é proposta por Ballweg. Procuro de qualquer forma me manter fiel aos seus propósitos, apenas ampliando a análise de forma a compreender as diversas retóricas da teoria jurídica no que se refere às construções que determinam relações entre sujeitos, objetos e sinais.

\title{
CONCLUSÃO
}

A partir de uma analogia entre os três níveis da retórica e os três níveis do direito, procurei esboçar uma teoria retórica do direito. O esquema da retórica analítica foi empregado como modelo de compreensão da própria atividade teórica de reflexão sobre o direito.

Dessa forma, poderíamos falar em três níveis distintos do direito: o nível técnico de sua retórica material, o nível tecnológico de sua retórica prática e o nível teórico de sua retórica analítica. 


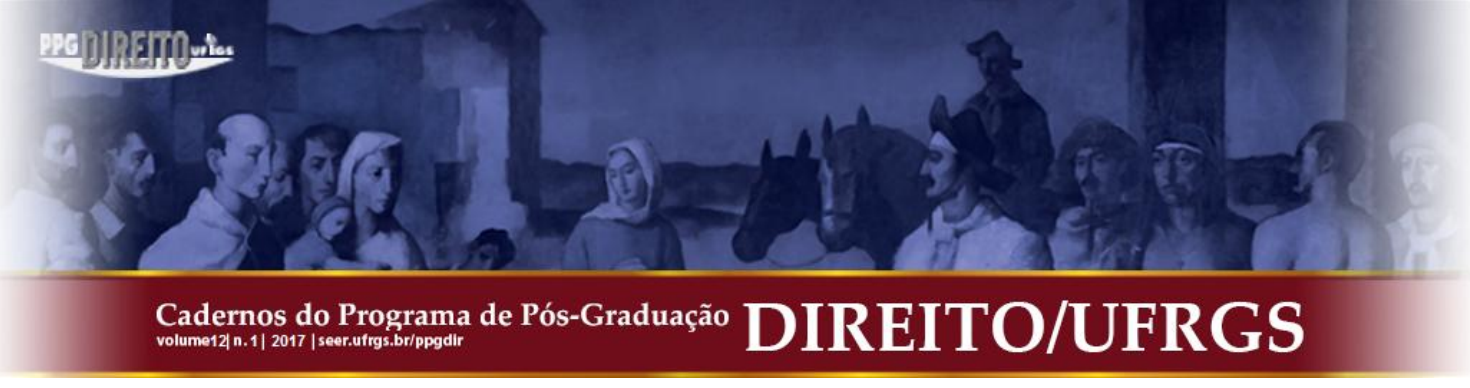

A proposta de análise retórica é, pois, a de investigar o direito a partir de seus discursos, vocabulários e narrativas, colocando, assim, a linguagem no centro das atenções. São as "palavrinhas" que interessam antes de tudo a uma teoria retórica. Sempre ligadas, claro, à necessidade de persuasão de cada situação retórica específica.

Uma teoria retórica do direito propõe, portanto, um exame do discurso jurídico não como mero acessório da atividade de reflexão sobre o direito, mas como principal ingrediente da própria noção de direito. A ideia é que os elementos que constituem a retórica do direito possam ser investigados analiticamente por meio da fronética, da holotática e da semiótica.

\section{REFERÊNCIAS}

ADEODATO, João Maurício. A retórica constitucional. Sobre tolerância, direitos humanos e outros fundamentos éticos do direito positivo. São Paulo: Saraiva, 2009. UENP, 2013.

Retórica analítica como metódica jurídica. Argumenta, n. 18, p. 11-29, Jacarezinho:

ARISTÓTELES. Retorica. Tradução de Marco Dorati. Milano: Mondadori, 1996.

BALLWEG, Ottmar. Analytische Rhetorik als juristische Grundlagenforschung. In: ALEXY, R; DREIER, R; NEUMANN, U. (Hrsg.). Archiv für Rechts- und Sozialphilosophie. Beiheft 44. Stuttgart: Franz Steiner Verlag, 1991a, p. 45-54.

. Entwurf einer analytischen Rhetorik. In: SCHANZE; KOPPERSCHMIDT (Hrsg.). Rhetorik und Philosophie. München: Wilhelm Fink Verlag, 1989, p. 229-247.

Phronetik, Semiotik und Rhetorik. In: BALLWEG, Ottmar; SEIBERT, ThomasMichael (Hrsg.). Rhetorische Rechtstheorie. Freiburg/München: Verlag Karl Alber, 1982, p. 27-71.

Retórica analítica e direito. Tradução de J. M. Adeodato. Revista Brasileira de Filosofia, v. XXXIX, Fasc. 163, jul-ago-set, 1991b, p. 175-184.

FERRAZ Jr., Tercio Sampaio. Função social da dogmática jurídica. São Paulo: RT, 1980.

JHERING, Rudolf von. Bromas y veras en la jurisprudencia. Un regalo de Navidad para los lectores de obras jurídicas. Tradução de T. A. Banzhaf. Ediciones Jurídicas Europa-America: Buenos Aires, 1974.

LAUNHARDT, Agnes. Topik und rhetorische Rechtstheorie. Eine Untersuchung zu Rezeption und Relevanz der Rechtstheorie Theodor Viehwegs [Dissertation zur Erlangung des 


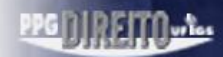 \\ Cadernos do Programa de Pós-Graduação
volume12 n.1| 2017 | seer.utrgs.br/ppgdir}

Doktorgrades der Juristischen Fakultät der Heinrich-Heine-Universität Düsseldorf]. Düsseldorf, 2005.

NIETZSCHE, Friedrich Wilhelm. Rhetorik. Darstellung der antiken Rhetorik; Vorlesung Sommer 1874, dreistündig. Gesammelte Werke. Band 5. München: Musarion Verlag, 1922.

PARINI, Pedro. Ironia e metáfora na filosofia do direito. In: NÓBREGA, F. F. B.; MARINHO, C.; BASTOS Jr., R. C. (Orgs.). Pragmatismo jurídico. Fundamentos e métodos de uma doutrina interdisciplinar. Recife: UFPE, 2014, p. 621-652.

Retórica como método no direito. O entimema e o paradigma como bases de uma retórica judicial analítica. João Pessoa: EDUFPB, 2015.

Submissão: 19/04/2017

Aceito para Publicação: 03/08/2017 


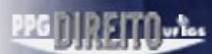

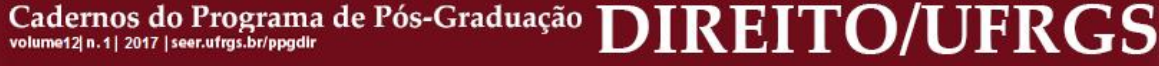

135 